\title{
Fabrication of Carbon-Carbon Composites by Using \\ Carbon Fibers Impregnated with Resin and \\ Their Mechanical Properties*
}

\author{
By Tongshik CHANG** and Akimitsu OKURA ${ }^{* *}$
}

\begin{abstract}
Synopsis
A carbon-carbon $(\mathrm{G} / \mathrm{C})$ composite was fabricated in laboratory by means of a simple hot-press process using fine pulverized coke and carbonaceous bulk mesophase (BM) as matrix and resin-impregnated, unidirectional long carbon fibers (UD fibers) and cloths as reinforcement. Maximum temperature and pressure in hot-press process were carried out at $600^{\circ} \mathrm{C}$ and $49 \mathrm{MPa}$, respectively. When two types of UD fibers (of $U D-1$ and $U D-2)$ are used, the maximum strength of primary products is obtained at the BM ratio in matrix $70 \%$ and with the $V_{f}$ value $30 \%$ in case with UD-1 and at the BM ratio $80 \%$ and with the $V_{f}$ value $46.4 \%$ in case with UD-2, the latter being a little higher. When two types of cloths (of $C L-1$ and $C L-2$ ) are used, the strength is maximum at the $V_{f}$ value $20 \%$ in both cases, which is however much lower than the maximum strength when UD fibers are used. Primary products reinforced by UD-2 and CL-2 lose their strengths through heat treatment. As far as primary products using UD fibers are concerned, the maximum strength marks 119 and $130 \mathrm{MPa}$ for UD-1 and UD-2, respectively, which are higher than the strength of the commercial $\mathrm{C} / \mathrm{C}$ composite.
\end{abstract}

Key words: composite material; carbon-carbon composite; hot pressing; strength; carbonaceous mesophase; reinforcement; unidirectional carbon fiber.

\section{Introduction}

The authors tried to fabricate carbon fiber reinforced carbon composites (G/G composites) by a simple process compared with known methods. ${ }^{1,2)}$ In this process, admixture of fine pulverized coke and a binder material as matrix was laminated alternately with carbon fibers in a die to be followed by a hot press process, which provides simple fabrication of $\mathrm{G} / \mathrm{G}$ composites in a short time. The authors have already experimented in fabrication of $\mathrm{G} / \mathrm{C}$ composites using coal tar pitch ${ }^{3)}$ and easy-to-handle carbonaceous bulk mesophase, ${ }^{4)}$ called BM hereinafter, as binder for pulverized coke, wherein the use of BM did not yield any acceptable high strength because the matrix could not permeate sufficiently into bundles of carbon fibers, which may originate from the fact that BM softens with heating but its viscosity at the time of softening remains high. Even when BM is used as binder, however, its combination with resin-impregnated carbon fibers will provide a more dense $\mathrm{G} / \mathrm{G}$ composite, because the bundles of fibers in their interior are bound together by a resin matrix while the fibers and carbonic matrix are bound fast between themselves through bond of the resin with BM. This implies that there is still a room for the strength to be enhanced.

Now, this study was to fabricate $\mathrm{G} / \mathrm{G}$ composite using $\mathrm{BM}$ as binder and carbon fibers which had been impregnanted with resin.

\section{Experimental Procedure}

\section{Material Used}

Coke powders as used for matrix are taken from pitch coke of coal origin, finely pulverized into particles of $3.5 \mu \mathrm{m}$, while carbonaceous bulk mesophase (BM) as used for binder was of $33.5 \%$ volatile matter. The use of these matrix materials was determined from a preliminary experiment as follows. In order to determine the optimum type and particle size of a coke and the optimum type of BM as matrix, only baked blocks of matrix were produced. The matrix materials used are two types of cokes (of coal origin $^{5)}$ and petroleum origin) which were pulverized at three stages and two types of BM (of petroleum origin) in which a volatile matter content is different. The bending strength of matrix thus obtained was investigated. The results indicated that the maximum matrix strength was obtained when the pitch coke of coal type with the least particle size $(3.5 \mu \mathrm{m})$ and the $\mathrm{BM}$ with the highest volatile matter content $(33.5 \%)$ were used. From these results, the abovementioned matrix materials were adopted.

Carbon fibers as used for reinforcement were products of Nippon Carbon Co., Ltd. made in the form of sheets which had been impregnated with epoxy resin (hereinafter expressed simply as "prepreg sheet"). They were prepared in two types, unidirectional long fibers (called UD fibers) and cloth forms (called CL forms), each with two different thicknesses. The data for these prepreg sheets are given on Table 1. The thinner UD fiber is represented by UD-1 and the thicker one UD-2, while the thinner cloth is designated as GL-1 and the thicker one GL-2.

\section{Fabricating Procedure}

The procedure for preparing $\mathrm{G} / \mathrm{G}$ composite is shown in Fig. 1. The above-mentioned different types of resin-impregnated prepreg sheets were cut into squares of $50 \times 50 \mathrm{~mm}$ and laminated alternately in a die with one of the matrix admixtures, which had been prepared in various mix proportions, and the yield was baked in a hot press (called at this stage a primary product) to be then subjected to high-temperature heat treatment. The heat treatment was made for only those of the primary products, which

* Based on the paper presented to the 111 th ISIJ Meeting, April 1986, S712, at The University of Tokyo in Tokyo. Manuscript received on August 20, 1986; accepted in the final form on December 12, 1986. (C) 1987 ISIJ

** Institute of Industrial Science, The University of Tokyo, Roppongi, Minato-ku, Tokyo 106. 
Table 1. Standard specification of unidirectional long carbon fibers and cloths impregnated with resin.

\begin{tabular}{|c|c|c|c|c|c|c|c|c|c|c|c|}
\hline \multicolumn{4}{|c|}{ (a) Unidirectional long fibers* } & \multicolumn{8}{|c|}{ (b) Cloths* } \\
\hline Kinds & Brands & $\begin{array}{c}\text { Epoxy resin } \\
\text { content } \\
(\%)\end{array}$ & $\begin{array}{c}\text { Thickness } \\
(\mathrm{mm})\end{array}$ & Kinds & Brands & $\begin{array}{c}\text { Woven } \\
\text { structure }\end{array}$ & $\begin{array}{c}\text { Warp.Fill } \\
\text { (yarn } \\
\text { count/ } \\
\text { inch) }\end{array}$ & $\begin{array}{l}\text { Fila- } \\
\text { ments/ } \\
\text { yarn }\end{array}$ & $\begin{array}{c}\text { Epoxy } \\
\text { resin } \\
\text { content } \\
(\%)\end{array}$ & $\begin{array}{l}\text { Weight } \\
\left(\mathrm{g} / \mathrm{m}^{2}\right)\end{array}$ & $\begin{array}{c}\text { Thick- } \\
\text { ness } \\
(\mathrm{mm})\end{array}$ \\
\hline UD-1 & RM-125 & $37.5 \pm 2.5$ & 0.125 & GL-1 & 3120 & Plain & 12.5 & 3000 & 38.5 & 200 & 0.2 \\
\hline UD-2 & RM-200 & $35 \pm 2.5$ & 0.2 & CL-2 & 6130 & weave & 9 & 6000 & 38.0 & 300 & 0.3 \\
\hline
\end{tabular}

* From catalog of Nippon Carbon Co., Ltd.

[ MATRIX ] [ CARBON FIBER ]

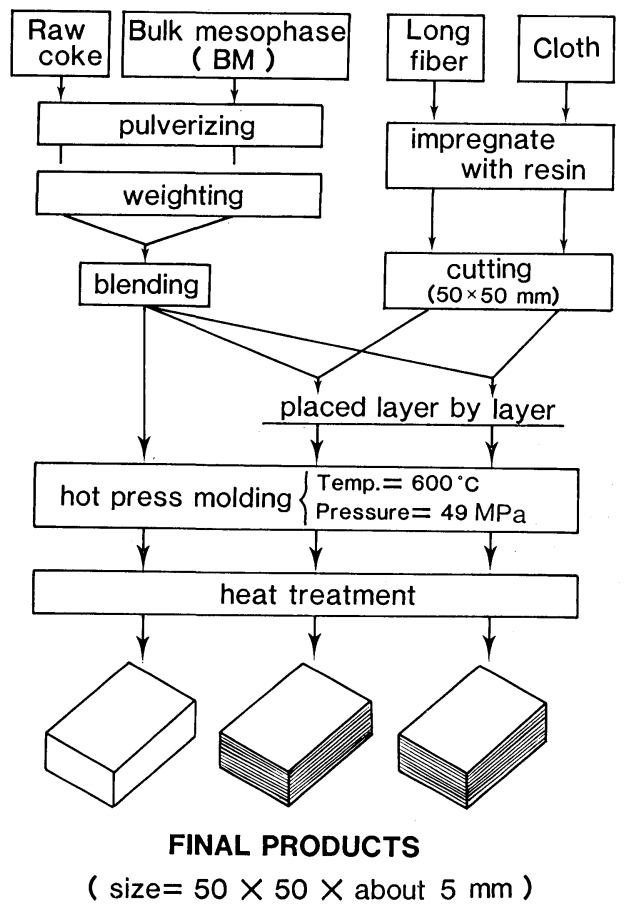

Fig. 1. Fabricating process of $\mathrm{C} / \mathrm{G}$ composites.

had exhibited the highest strength in a bending test at the stage after hot press baking.

The heat treatment of each primary product was so made as embedding each specimen in coke powders, heating to a certain specified temperature for $30 \mathrm{~min}$ in the atmosphere of $\mathrm{N}_{2}$ gas. The heating rate was $5^{\circ} \mathrm{C} / \mathrm{min}$ up to $550^{\circ} \mathrm{C}, 0.5^{\circ} \mathrm{C} / \mathrm{min}$ from 550 to $1000^{\circ} \mathrm{C}$, $1^{\circ} \mathrm{G} / \mathrm{min}$ from 1000 to $1200^{\circ} \mathrm{C}$, and $2^{\circ} \mathrm{C} / \mathrm{min}$ from 1200 to $1500^{\circ} \mathrm{C}$.

\section{Measurement of Physical Properties and Observation}

Apparent density $\left(\rho_{A}\right)$ of each specimen was calculated from the weight and the volume determined by water substitution method. The bending strength $\left(\sigma_{\max }\right)$ was determined by three-point bending test with $20 \mathrm{~mm}$ span on a specimen of approximately $5 \mathrm{~mm}$ thickness and $8 \mathrm{~mm}$ width. The cross-head speed was $1 \mathrm{~mm} / \mathrm{min}$. The bending modulus of elasticity $(E)$ was determined from the straight portion of the load-deflection curve. The testing machine used was Shimadzu's Autograph Type IS2000.

Three specimens of those samples which had under- gone bending test were subjected to microscopic observations. They were fixed with resins, and, after surface grinding and polishing, observations were made on the specimens with a reflex polarization microscope at a magnification of 200 .

A commercial $\mathrm{G} / \mathrm{C}$ composite was examined in the same manner for comparison with those fabricated experimentarily.

\section{Results and Discussion}

\section{Optimum Hot-press Condition}

Maximum temperature and pressure in hot-press process were held constant at $600^{\circ} \mathrm{C}$ and $49 \mathrm{MPa}$, respectively, while the heating rate, heating condition and pressure boosting condition were varied in three levels, and a hot pressing condition to yield a primary product having the maximum strength among these three conditions was taken as the optimum condition.

Under hot-press condition I: The temperature was raised up to $500^{\circ} \mathrm{C}$ at $13^{\circ} \mathrm{C} / \mathrm{min}$ to be kept there until elimination of decomposition gas generation was ascertained. After elimination of decomposition ga a preliminary boosting was made at $9.8 \mathrm{MPa}$ for $1 \mathrm{~min}$, and then the pressure was boosted to a certain specific level (49 $\mathrm{MPa})$. After attainment of $500^{\circ} \mathrm{C}$, this boosted pressure was held $20 \mathrm{~min}$. The temperature was raised again up to $600^{\circ} \mathrm{C}$ and kept for $20 \mathrm{~min}$, to be followed by natural cooling under compressed condition. When the die temperature was sunk below $300^{\circ} \mathrm{C}$, the pressure was relieved and the specimen was taken out. Under Condition II: The temperature was raised up to $125^{\circ} \mathrm{C}$ (the level required to harden resin) at $7^{\circ} \mathrm{C} / \mathrm{min}$ and kept there for $15 \mathrm{~min}$ to be followed by subsequent heating up to $500^{\circ} \mathrm{G}$ at $13^{\circ} \mathrm{G} / \mathrm{min}$. The heating condition and pressure boosting condition thereafter were the same as Condition I. Condition III is the same as II, provided that a preliminary boosting was made at 9.8 $\mathrm{MPa}$ while the temperature was held at $125^{\circ} \mathrm{C}$ for $15 \mathrm{~min}$.

Figure 2 -shows the relation between bending strength and the $\mathrm{BM}$ ratio in matrix of primary products baked under varied hot-press conditions with the $V_{f}$ value of the fibers (UD-1) held approximately constant $\left(V_{f} \doteqdot 8 \%\right)$. The curves indicate clearly that Condition I gives higher strengths for all $\mathrm{BM}$ ratios. The mean strength $\sigma_{\max }$ shown by the solid line in the figure is higher with higher BM ratio. In the case of the specimen with $\mathrm{BM}$ ratio 


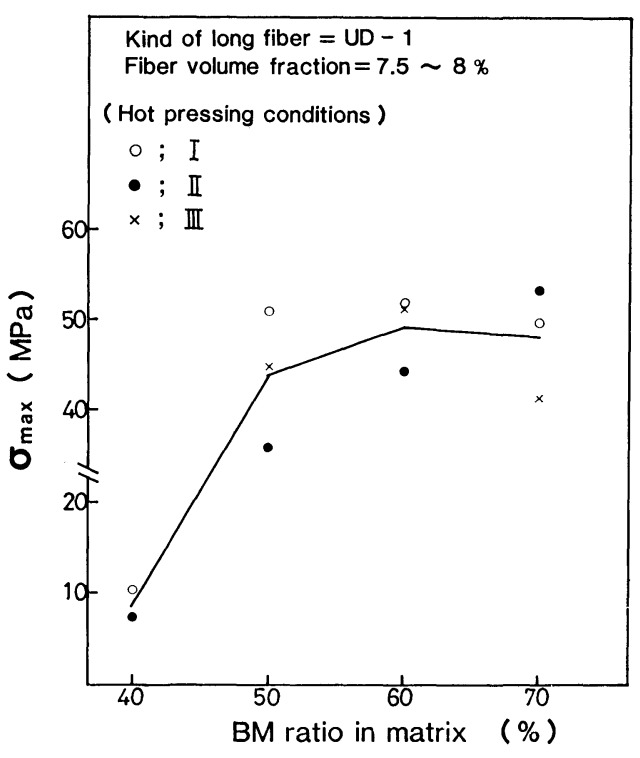

Fig. 2. Relation between BM ratio in matrix and bending strength $\left(\sigma_{\max }\right)$ of primary products molded by each hot pressing conditions.

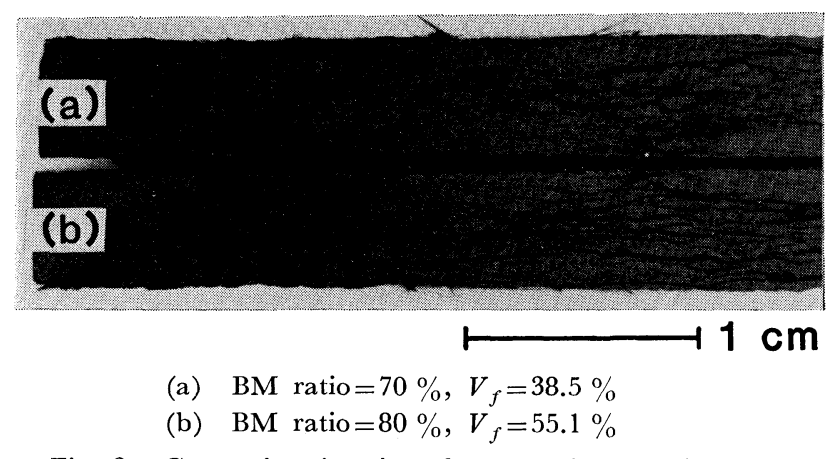

Fig. 3. Generating situation of separate layers at boundary between matrix and fibers on a $\mathrm{C} / \mathrm{C}$ composite end faces using UD-2 fibers.
$40 \%$, separate layers, similar to those seen in Fig. 3, are observed at the boundary between matrix and fibers on the specimen end faces. Accordingly the specimen with the $\mathrm{BM}$ ratio $40 \%$ exhibits an extremely low strength, which is probably due to generation of separate layers.

From these results, Condition I was adopted as hot-press condition for producing $\mathrm{C} / \mathrm{C}$ composites thereafter, and it was also decided that the $\mathrm{BM}$ ratio in matrix was no less than $60 \%$.

\section{Properties of Primary Products}

1. With UD Fibers

(1) Bonding Situation in Primary Product

It was described in Sec. III. 1 that a BM ratio in matrix less than $40 \%$ causes generation of a separate layer at the boundary between the matrix and fibers, in case UD- 1 is used $\left(V_{f} \fallingdotseq 8 \%\right)$. Here an examination is made to know to which level of $V_{f}$ value the fibers (UD-1, UD-2) can be laminated in order to make a primary product free from generation of a separate layer at the boundary between matrix and fibers, in case the BM ratio in matrix is increased over $60 \%$. The results obtained are shown on Table 2. The specimens represented by mark $x$ in this table indicated that the generation of separate layers as shown in Fig. 3 are observed.

This table says that generation of separate layers is observed when the $V_{f}$ value exceeds a certain level, regardless of the BM ratio in both cases with UD-1 and UD-2. It can be known also that the $V_{f}$ value, at which separate layers are generated, increases with increasing the BM ratio in both cases with UD-1 and UD-2, and that the UD-2 requires larger $V_{f}$ value for such generation than the UD-1, comparing at the same $\mathrm{BM}$ ratio.

Table 2. Bonding situation of primary baking products with change of volume fraction of long fibers.

\begin{tabular}{|c|c|c|c|c|c|c|}
\hline \multicolumn{3}{|c|}{ Matrix } & \multicolumn{4}{|c|}{ Kinds of long fibers } \\
\hline \multirow{2}{*}{ Coke } & \multirow{2}{*}{$\begin{array}{l}\text { Binder } \\
\text { ratio } \\
(\%)\end{array}$} & \multirow{2}{*}{$\begin{array}{l}\text { Volatile } \\
\text { matter } \\
(\%)\end{array}$} & \multicolumn{2}{|c|}{ UD-1 } & \multicolumn{2}{|c|}{ UD-2 } \\
\hline & & & $V_{f}(\%)$ & $\begin{array}{l}\text { Bonding } \\
\text { situation }\end{array}$ & $V_{f}(\%)$ & $\begin{array}{l}\text { Bonding } \\
\text { situation }\end{array}$ \\
\hline \multirow{8}{*}{$\begin{array}{c}\text { Pitch coke } \\
\text { (particle } \\
\text { size }=3.5 \mu \mathrm{m})\end{array}$} & 60 & 20.32 & $\begin{array}{c}7.7 \sim 25.8 \\
34.2\end{array}$ & $\begin{array}{l}0 \\
\times \\
\end{array}$ & - & - \\
\hline & \multirow[t]{2}{*}{70} & \multirow[t]{2}{*}{23.62} & $\begin{array}{c}8.3 \sim 29.2 \\
33.2\end{array}$ & $\begin{array}{l}0 \\
\times\end{array}$ & $19.1 \sim 31.8$ & 0 \\
\hline & & & - & - & 38.5 & $x$ \\
\hline & \multirow{2}{*}{80} & \multirow{2}{*}{26.91} & $\begin{array}{c}17.8 \sim 33.2 \\
42.2\end{array}$ & $\begin{array}{r}0 \\
\times \\
\end{array}$ & $19.9 \sim 40.2$ & 0 \\
\hline & & & - & - & $\begin{array}{l}46.4 \\
55.1 \\
\end{array}$ & $\begin{array}{r}0 \\
\times \\
\end{array}$ \\
\hline & \multirow{2}{*}{90} & \multirow{2}{*}{30.21} & $\begin{array}{c}17.4 \sim 36.7 \\
40.4\end{array}$ & $\begin{array}{l}0 \\
\times\end{array}$ & $19.2 \sim 37.3$ & $\mathrm{O}$ \\
\hline & & & - & - & $\begin{array}{l}46.1 \\
55.6\end{array}$ & $\begin{array}{l}0 \\
\times\end{array}$ \\
\hline & 100 & 33.50 & $\begin{array}{c}24.6 \sim 41.1 \\
53.8\end{array}$ & $\begin{array}{l}0 \\
\times\end{array}$ & $\begin{array}{c}27.0 \sim 44.8 \\
54.3\end{array}$ & $\begin{array}{l}0 \\
\times\end{array}$ \\
\hline
\end{tabular}

$O$ : none crack $x$ : none bonding 
Therefore the $V_{f}$ value of each specimen as primary products for $\mathrm{G} / \mathrm{G}$ composites using prepreg sheets of resin-impregnated unidirectional long fibers can be raised by increasing the $\mathrm{BM}$ ratio in the matrix, and also by using thicker prepreg sheets in case such having the same $V_{f}$ value are laminated with BM ratio held constant.

(2) Properties of G/G Composite

Figures 4 and 5 show the relationship between the $V_{f}$ value of the fibers in primary products produced with varied $\mathrm{BM}$ ratio in the matrix and the resultant bending strength $\left(\sigma_{\max }\right)$, Young's modulus $(E)$ and apparent density $\left(\rho_{A}\right)$. The bending strength increases with $V_{f}$ value regardless of $\mathrm{BM}$ ratio to a certain point, and then decreases with $V_{f}$ value in both cases with UD-1 and UD-2 as indicated in these figures. Such drop in strength happens only on the specimens (those on Table 2 marked $\times$ ) wherein a separate layer is generated at the boundary between matrix and fibers. Examination of the influence of $\mathrm{BM}$ ratio upon the resultant strength indicates that there is an optimum BM ratio which gives the maximum strength in both cases with UD-1 and UD-2a $\mathrm{BM}$ ratio of $70 \%$ with UD-1 gives the peak in the strength with the $V_{f}$ value ranging between 25 and $30 \%$, while $80 \%$ with UD-2 does the peak throughout the scope of $V_{f}$ value. The obtained values of strength with UD-1 and UD-2 are 119 and $130 \mathrm{MPa}$, respectively, which lie above the corresponding data of a commercial $\mathrm{G} / \mathrm{G}$ composite (100 MPa).

$\rho_{A}$ increases, on the other hand, with increasing $V_{f}$ value for the whole $\mathrm{BM}$ range in both cases with UD-1 and UD-2, the latter indicating more rapidly rising tendency. This increase of $\rho_{A}$ with $V_{f}$ is because density of fibers themselves $\left(1.77 \mathrm{~g} / \mathrm{cm}^{3}\right)$ is higher than that of the matrix only $\left(\rho_{A}\right.$; for example, no more than $1.4 \mathrm{~g} / \mathrm{cm}^{3}$ when $\mathrm{BM}$ ratio is $60 \%$ and $V_{f}$ is zero as in Fig. 4). If the $V_{f}$ held constant, $\rho_{A}$ decreases with increasing BM ratio in both cases with UD-1 and UD-2, that would be because the residual volatile matter in the specimen is greater with higher BM ratio.

Both the apparent density and bending strength increase with increasing $V_{f}$ value throughout the scope of $\mathrm{BM}$ ratio, in particular with UD-2, except those specimens whereon a separate layer is generated. The results implies that these two factors are correlated with each other, but there is no significant correlation between the changes of $\rho_{A}$ and $\sigma_{\max }$ in compliance with change in $\mathrm{BM}$ ratio when the $V_{f}$ value is held constant. Therefore it can be considered that the rise of $V_{f}$ value contributes more than the apparent density of the composite material to compensation of the strength of $\mathrm{C} / \mathrm{G}$ composite produced from UD fibers impregnated with resin. In Figs. 4 and 5 , the $\rho_{A}$ value of a commercial $\mathrm{C} / \mathrm{C}$ composite $\left(1.76 \mathrm{~g} / \mathrm{cm}^{3}\right)$ is inserted for comparison, which gives a clear knowledge that these experimentally fabricated $\mathrm{G} / \mathrm{G}$ composites have a lower apparent density than the commercial. Comparing by specific strength, therefore, the experimental product which exhibits the highest strength has a specific

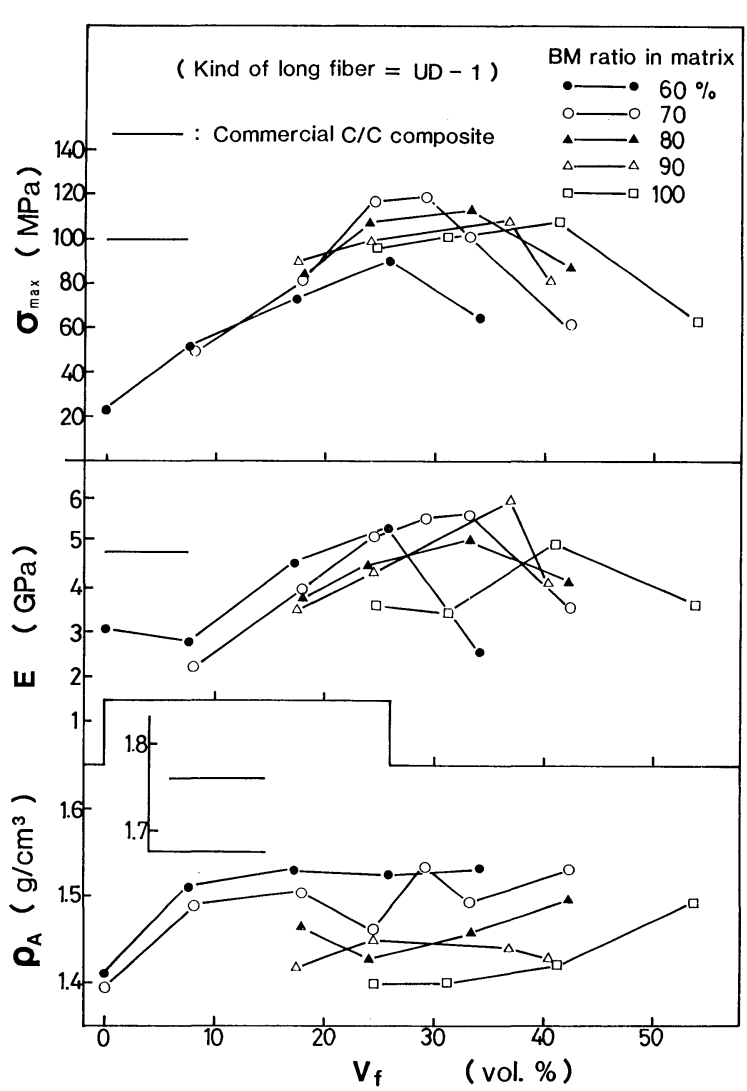

Fig. 4. Relation between volume fraction $\left(V_{f}\right)$ and bending strength $\left(\sigma_{\max }\right)$, Young's modulus $(E)$, and apparent density $\left(\rho_{A}\right)$ of primary products.

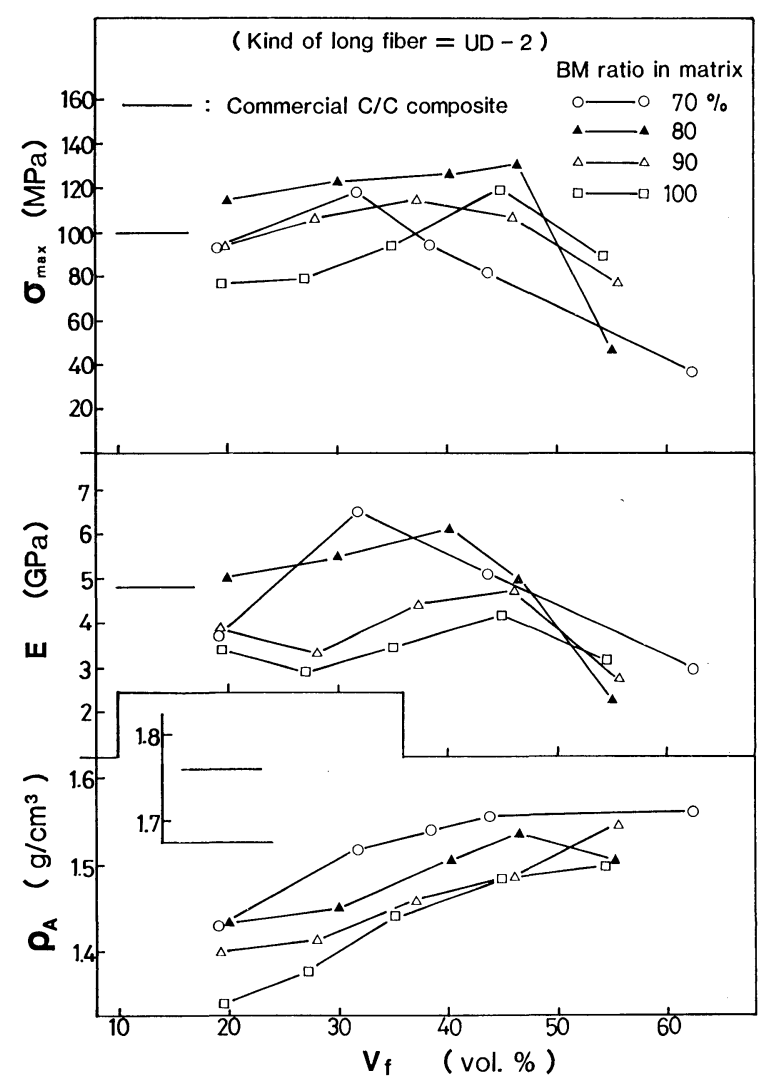

Fig. 5. Relation between volume fraction $\left(V_{f}\right)$ and bending strength $\left(\sigma_{\max }\right)$, Young's modulus $(E)$, and apparent density $\left(\rho_{A}\right)$ of primary products. 
strength of $84.7 \mathrm{MPa} / \mathrm{g}$ (with UD-2, $V_{f} 46.4 \%$ and $\mathrm{BM}$ ratio $80 \%$ ). This value corresponds to approximately 1.5 times of that of the commercial $\mathrm{G} / \mathrm{C}$ composite.

\section{With Gloth}

Primary products with cloths were prepared first with the $V_{f}$ value of fibers held constant (approximately $20 \%$ ), and the influence of the $\mathrm{BM}$ ratio in each matrix upon their strengths was examined. The peak of strength was seen with a $\mathrm{BM}$ ratio of 80 to $90 \%$ in the case of CL-1, and 70 to $80 \%$ in the case of CL-2. To examine the influence of the $V_{f}$ value upon the strength of primary products, the BM ratio was set to $90 \%$ in the case of CL-1, and to 70, $80 \%$ in the case of CL-2 as well as $60 \%$ for the purpose of comparing with the matrix only $\left(V_{f}=0\right)$. The results are shown in Fig. 6. According to the figure, the strength increases with increasing $V_{f}$ value up to around $20 \%$ for every $\mathrm{BM}$ ratio used in the experiment, and decreases thereafter in case with GL-2, while no significant change in strength can be discerned in case with GL-1. The strength of these $\mathrm{G} / \mathrm{C}$ composites is, in fact, higher than that of the matrix only $\left(V_{f}=0\right)$, but their maximum strengths read about $40 \mathrm{MPa}$ in both cases with CL-1 and GL-2 (BM ratio $80 \%$ ), being much lower than the strength of composites using UD fibers.

\section{Influence of Hot-press Pressure upon Strength of Primary Product}

The examination was made for only those of the fabricating condition which had exhibited a com-

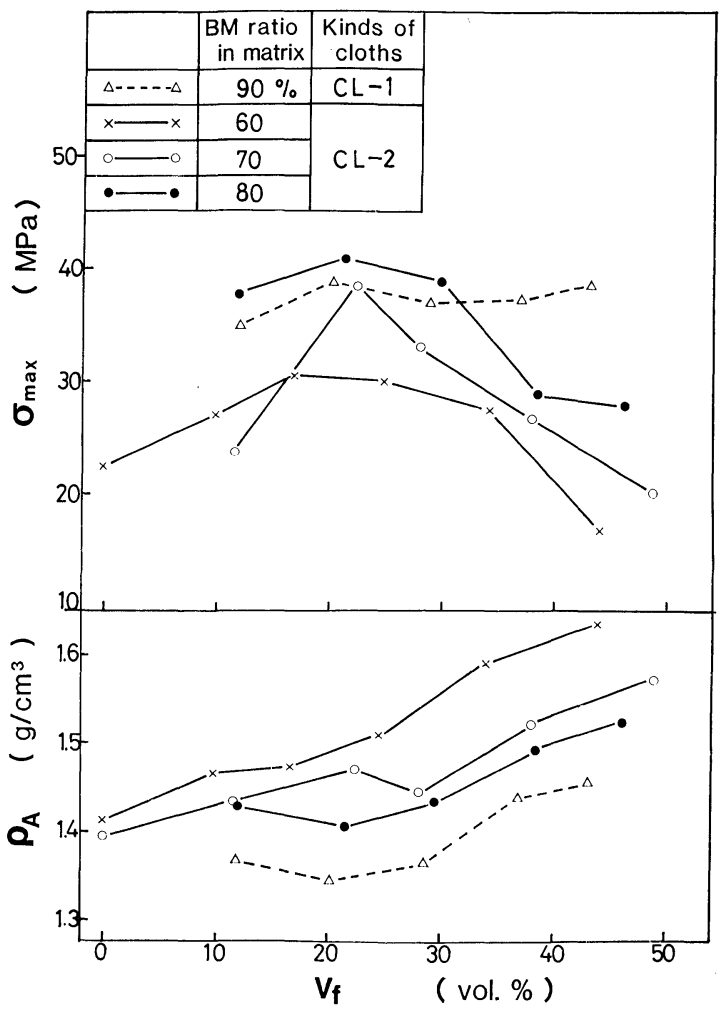

Fig. 6. Bending strength $\left(\sigma_{\max }\right)$ and apparent density $\left(\rho_{A}\right)$ of primary products as function of volume fraction $\left(V_{f}\right)$ of cloths. paratively high strength among the primary products made under the various fabricating conditions of the foregoing experiments using UD fibers, that is, the type of fiber used was UD-2, BM ratio $80 \%$, and $V_{f}$ values 30 and $45 \%$.

Figure 7 shows the change of bending strength, weight loss and apparent density with a change in the hot pressing pressure in primary products using UD-2. According to the figure, the strength of primary products maximizes at the hot-press pressure $49 \mathrm{MPa}$ for both selected $V_{f}$ values 30 and $45 \%$. The specimen with the $V_{f}$ value $45 \%$ exhibits a remarkable strength drop over a pressure of $73.5 \mathrm{MPa}$ may be due to generation of separate layers, which were observed on the specimens at the boundary between matrix and fibers.

It can be known also from this figure that there is a correlation between the weight loss and apparent density of the specimens having the $V_{f}$ value $30 \%$, when the hot-press pressure applied is varied, while no significant correlation is discerned between the apparent density and bending strength. Accordingly the increase in the bending strength can be attributed to the change in apparent density within the pressure range less than $49 \mathrm{MPa}$, while the strength drop under the pressure above $73.5 \mathrm{MPa}$ can not be interpreted solely by the change in the apparent density, and the mechanism is not clear at all.

\section{Influence of Heat Treatment Temperature upon Physical Properties of Composite}

The examination was made on those specimens having a comparatively high strength among primary products using UD fibers or cloths.

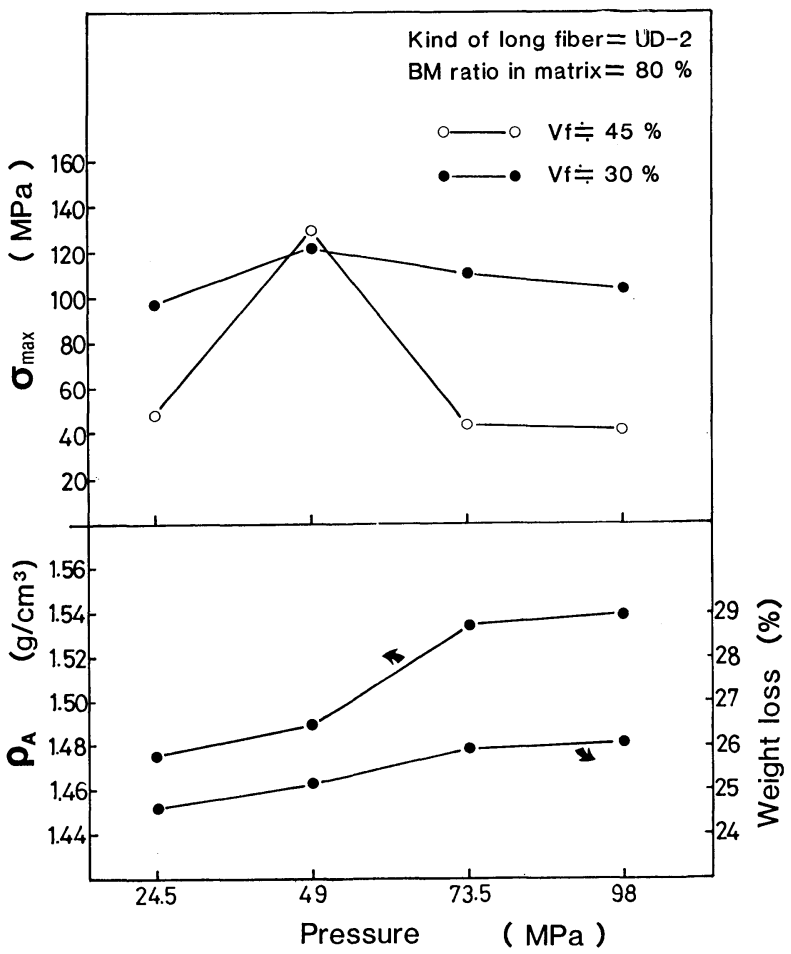

Fig. 7. Change of weight lose, apparent density $\left(\rho_{A}\right)$, and bending strength $\left(\sigma_{\max }\right)$ of primary products with hot pressing pressure. 
Figure 8 shows the change of bending strength, apparent density, shrinkage and weight loss of primary products using UD-2 and CL-2 with heat treatment temperature (represented by HTT hereinafter). Figure 8 indicates that weight loss, shrinkage and apparent density increase with HTT in both cases with UD fibers and cloth, while the bending strength decreases in the same environment. It can also be known that there is correlation between the shrinkage and apparent density in their changing behavior in linkage with the rise of HTT in both cases with UD fiber and cloth. Accordingly the increase in the apparent density of such specimens with rising HTT is due to shrinkage of the material with rise of HTT, which is related to weight loss.

The strength drop noticed when HTT is going up is remarkable in the HTT range between 600 and $700^{\circ} \mathrm{G}$ in both cases using UD-2 and GL-2 which is followed by a substantially flattened portion in each curve. The specimens after heat treatment were cut, and their cross sections were subjected to observation with a polarization microscope. An ocular inspection on the section of those specimens using cloths has revealed that cracks are generated, which could be attributed to difference of the shrinkage factor between matrix and fibers. Thus the strength drop in this composite may be referred to generation of such cracks. Observation on the specimen sections

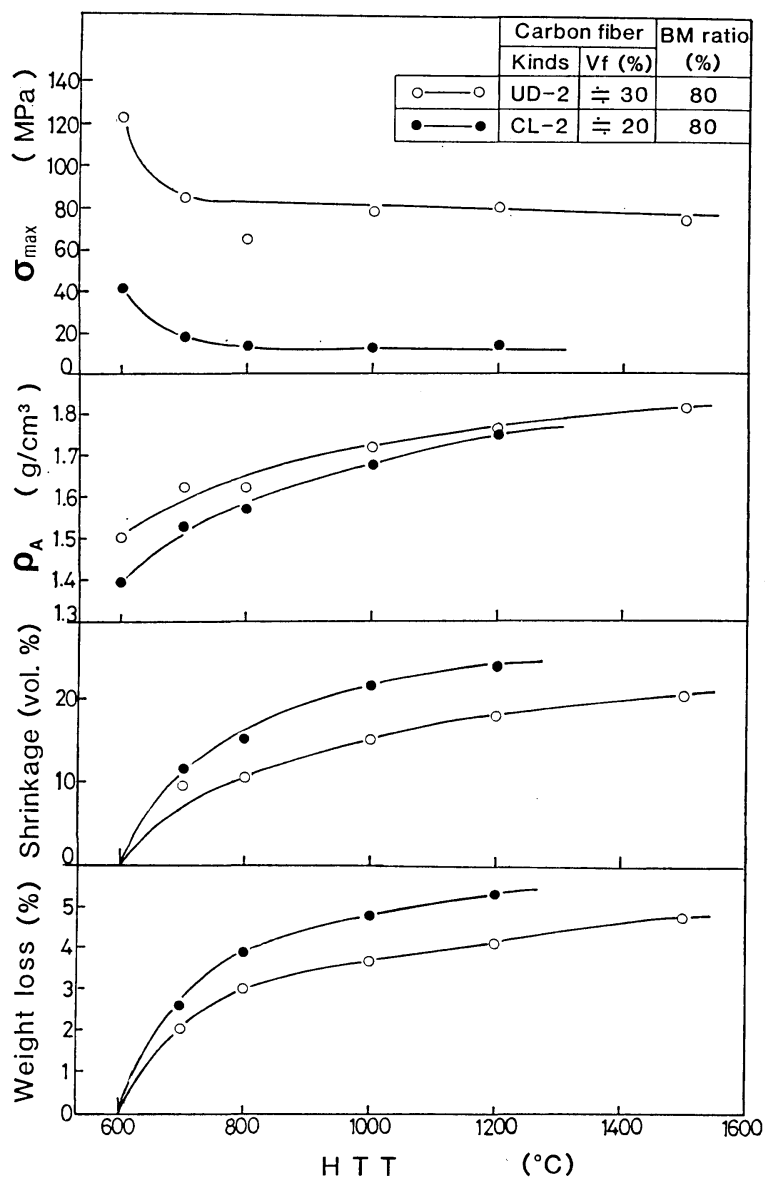

Fig. 8. Change of bending strength $\left(\sigma_{\max }\right)$, apparent density $\left(\rho_{A}\right)$, shrinkage, and weight loss of specimens with heat treatment up to $1500^{\circ} \mathrm{C}$. using UD fibers has revealed also that microcracks and separate layers are generated, so that the strength drop in this type of composite could be referred to generation of such cracks and separation. The results of observation on the specimens using UD fibers will be discussed in detail in a later chapter.

\section{Fracture Behavior of $\mathrm{G} / \mathrm{G}$ Composite}

Figure 9 shows load-deflection curves obtained from measurements on the bending strength of primary products using UD fibers and cloth, in comparison with one of the commercial $\mathrm{C} / \mathrm{C}$ composites. The matrix only showed brittle fracture, ${ }^{3)}$ but these specimens of $\mathrm{G} / \mathrm{C}$ composites have presented complicated load-deflection curves as known from the figure. The commercial $\mathrm{G} / \mathrm{G}$ composite ( $\mathrm{G}$ in the figure) has demonstrated a considerably large strength drop after the peak of load to be followed by gradual decrease of load. The specimen using UD fibers (A in the figure), on the other hand, has exhibited a peculiar fracture behavior in which the strength is kept a relatively high level after the peak of load to be followed by a stepped drop of the strength. The specimen using cloth (B in the figure) has given a much different pattern from the above two, in which no remarkable strength drop is perceived even after the peak of load, and the load decreases with a small ripple of up and down. It can be known that these experimentarily fabricated $\mathrm{C} / \mathrm{C}$ composites show different fracture behaviors by the form of the carbon fibers used.

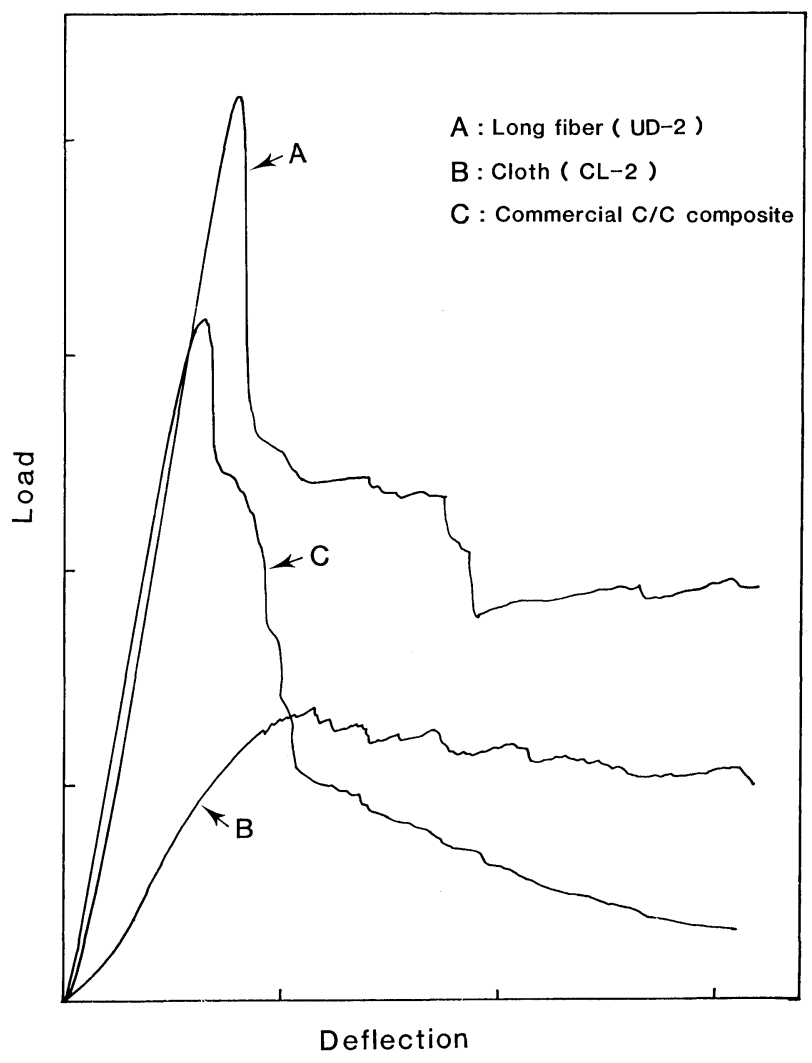

Fig. 9. Load-deflection curves of various $\mathrm{C} / \mathrm{C}$ composites hot-pressed at $600^{\circ} \mathrm{C}$ and $49 \mathrm{MPa}$. 
6. Knowledge from Polarization Microscope Observation on $\mathrm{G} / \mathrm{C}$ Composite of Trial Make

\section{Structure Observed on Gross Section of Primary} Product

Figure 10 shows polarized light microphotographs on the sections from specimens of primary products (corresponding to the specimens in Fig. 5 indicated by the mark $\boldsymbol{\Delta}$ ) for varying $V_{f}$ values of UD-2 fibers with the $\mathrm{BM}$ ratio in matrix held constant (at $80 \%$ ). A specimen section is shown by Photo A-1 in Fig. 10 for the $V_{f}$ value $19.9 \%$, by Photos A-1, A-2, and A-3 for the $V_{f}$ value $30.7 \%$, by Photos A-2 and A-3
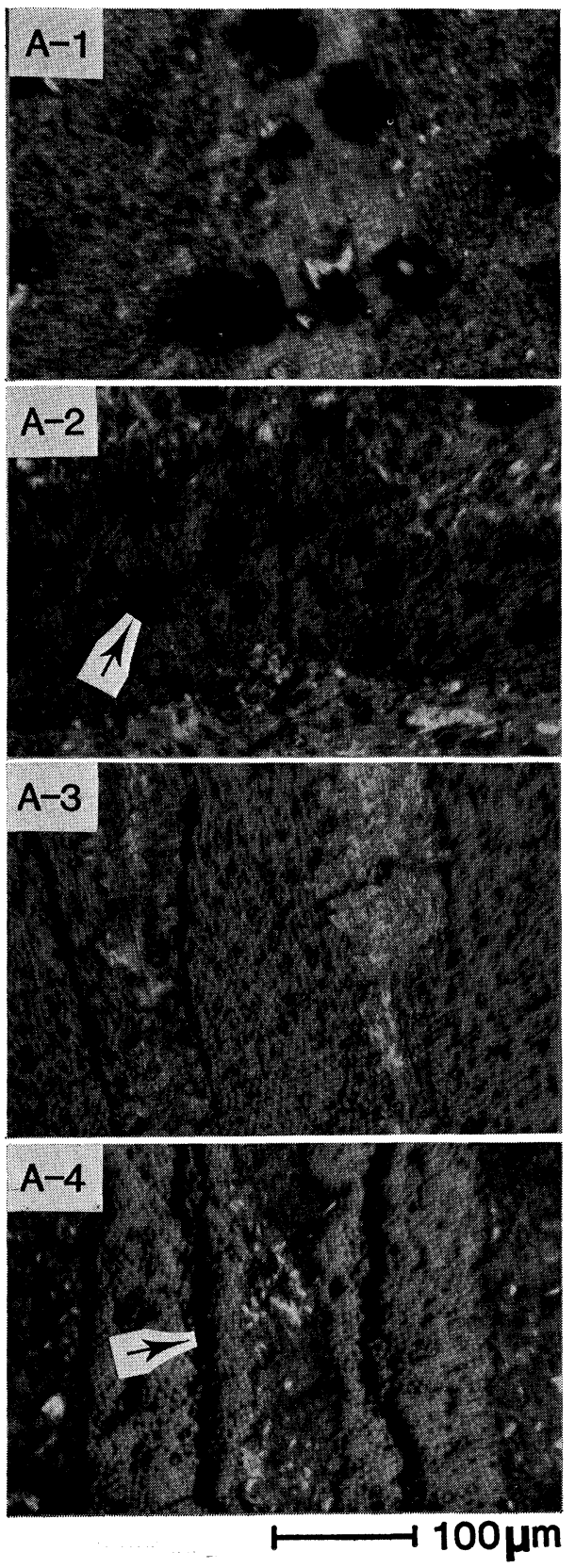

$$
\begin{aligned}
V_{f}=19.9 \%: & \mathrm{A}-1 \\
V_{f}=30.7 \%: & \mathrm{A}-1, \mathrm{~A}-2, \mathrm{~A}-3 \\
V_{f}=40.2,46.4 \%: & \mathrm{A}-2, \mathrm{~A}-3 \\
V_{f}=55.1 \%: & \mathrm{A}-4
\end{aligned}
$$

Fig. 10. Polarized light microphotographs of a $\mathrm{C} / \mathrm{C}$ composite cross section using UD-2 fibers $(\mathrm{BM}$ ratio= $80 \%$ ). for the $V_{f}$ values 30.7 and $46.4 \%$, and by Photo A-4 for the $V_{f}$ value $55.1 \%$.

In case the $V_{f}$ value of fibers is $19.9 \%$, the fibers are well dispersed in matrix as known from Photo A-1 on the figure, but pores of 25 to $50 \mu \mathrm{m}$ are observed in the matrix layers of all section provided. For the $V_{f}$ value $30.7 \%$, three different zones are discerned-a zone with good fiber dispersion as seen on Photo A-1, another with good bond at the boundary between the fiber layer and matrix, but including missing fibers in some areas (as shown by mark $\uparrow$ in Photo A-2), and the third, which is not large but in which matrices and fibers are laid one another in layers (Photo A-3). Generation of pores in the matrix layer, on the other hand, has a tendency that the diameter of pores is not significantly different from the one for the $V_{f}=19.9 \%$, but the whole amount of generated pores is less. For the $V_{f}$ values 40.2 and $46.4 \%$; they exhibit almost the identical structure on the section, where three different zones are perceived-zones identified by Photos A-2 and A-3, and the third where the matrix includes pores of $25 \mu \mathrm{m}$; in comparison to the case with $V_{f}=$ $30.7 \%$, the zone identified by Photo A-3 is greater and the amount of pores generated is less. For the $V_{f}$ value $55.1 \%$, the specimen in which a separate layer is generated at the boundary between fibers and matrix (see Table 2) has exhibited distinctly missing fiber parts and generation of longer microcracks (as shown by mark $\uparrow$ in Photo A-4) in almost all fiber layers.

In the same manner, section observation was made for varying $V_{f}$ value with the $\mathrm{BM}$ ratio held at $100 \%$ (corresponding to the specimens in Fig. 5 indicated by mark $\square$ ). Dispersion of fibers in the matrix is rather good for every $V_{f}$ value relative to the cases with $\mathrm{BM}$ ratio $80 \%$, but the specimen sections for all $V_{f}$ values have demonstrated generation of microcracks (as shown by mark $\uparrow$ in Photo B-1 on Fig. 11). Further, larger (Photo B-2) and more pores were observed than the cases with the $\mathrm{BM}$ ratio $80 \%$. From the results of observation, it was also known that generation of microcracks as indicated by Photo B-1 decreases with increasing $V_{f}$ value, and the pores by Photo B-2 $(100 \mu \mathrm{m})$ decrease their diameters with increasing $V_{f}$ value (reduced to 25 to $50 \mu \mathrm{m}$, when $V_{f}$ is $44.8 \%$ ).

It can generally be said in the case of $\mathrm{BM}$ ratio $100 \%$, by contrast to the cases with $\mathrm{BM}$ ratio $80 \%$, that microcracks are generated and more and larger pores are produced. This would have yielded the phenomenon as in Fig. 5 where $\sigma_{\max }$ reads low for all $V_{f}$ value considered in the case of $\mathrm{BM}$ ratio $100 \%$.

In both cases with $\mathrm{BM}$ ratio 80 and $100 \%$, pores diameters decrease with increasing $V_{f}$ value, and with $100 \%$ solely generation of microcracks reduces with increasing $V_{f}$ value, and these would constitute one reason for increase of $\sigma_{\max }$ with $V_{f}$ value in both cases with $\mathrm{BM}$ ratio 80 and $100 \%$ (see Fig. 5).

Figure 12 shows the observations on the sections of the specimens with cloth (CL-2) for $V_{f}$ values 21:5, 

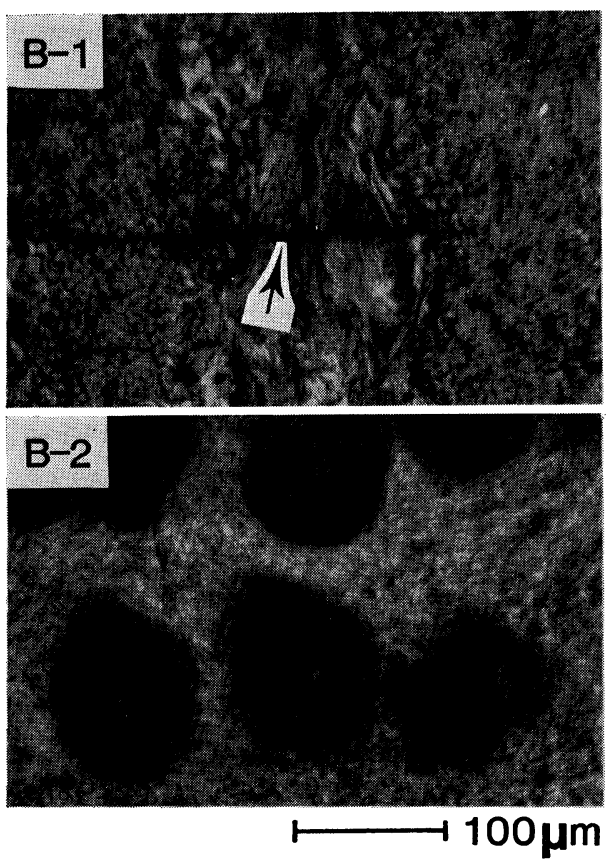

Fig. 11. Polarized light microphotographs of a $\mathrm{C} / \mathrm{C}$ composite cross section using UD-2 fibers (BM ratio $=100 \%, V_{f}=19.4 \%$ ).

29.5, and $38.5 \%$ with $\mathrm{BM}$ ratio held at $80 \%$ (corresponding to Fig. 6).

Observation of the residual condition of matrix in fiber layers, for $V_{f}=21.5 \%$, has revealed that there are two different zones. That is to say, there are much areas where the matrix has permeated in the fiber layers comparatively well (Photo G-2) and some areas where no matrix exists in the fiber layers as indicated by Photo G-1. At the boundary between fibers and matrix, parts with good bond (as shown by mark $\uparrow$ in Photo G-1) and the parts where separate layers are generated (as shown by mark $\uparrow$ in Photo G-3) are discerned in the proportion fifty to fifty. In almost all matrix layers, pores of $50 \mu \mathrm{m}$ as indicated by Photo G-4 and microcracks are perceived. For $V_{f}$ values 29.5 and $38.5 \%$, the bond at the boundary between fibers and matrix is good, and no separate layers as indicated by Photo G-3 are found. However, matrix permeability into the fiber layers as indicated by Photo G-2 worsens with increasing $V_{f}$ value. Generating situation of pores and cracks in matrix layers, for $V_{f}=29.5 \%$, is approximately the same as with $21.5 \%$ as described above, while, for $V_{f}=38.5 \%$, has produced two different zones in the proportion approximately 4 to 6 -i.e., one with pores in the matrix layers and the other without such - and both zones have demonstrated generation of microcracks as indicated by mark $\uparrow$ in Photo G-4, whose the amount is however minor to those presented by $V_{f}$ values 21.5 and $29.5 \%$.

On the specimens using cloth, thus, it can be known that there is no correlation between the changes of their section structures with bending strength in compliance with the change in $V_{f}$ value. Accordingly the drop of $\sigma_{\max }$ in compliance with change in $V_{f}$ value when GL-2 (BM ratio $80 \%$ ) is used as repre-
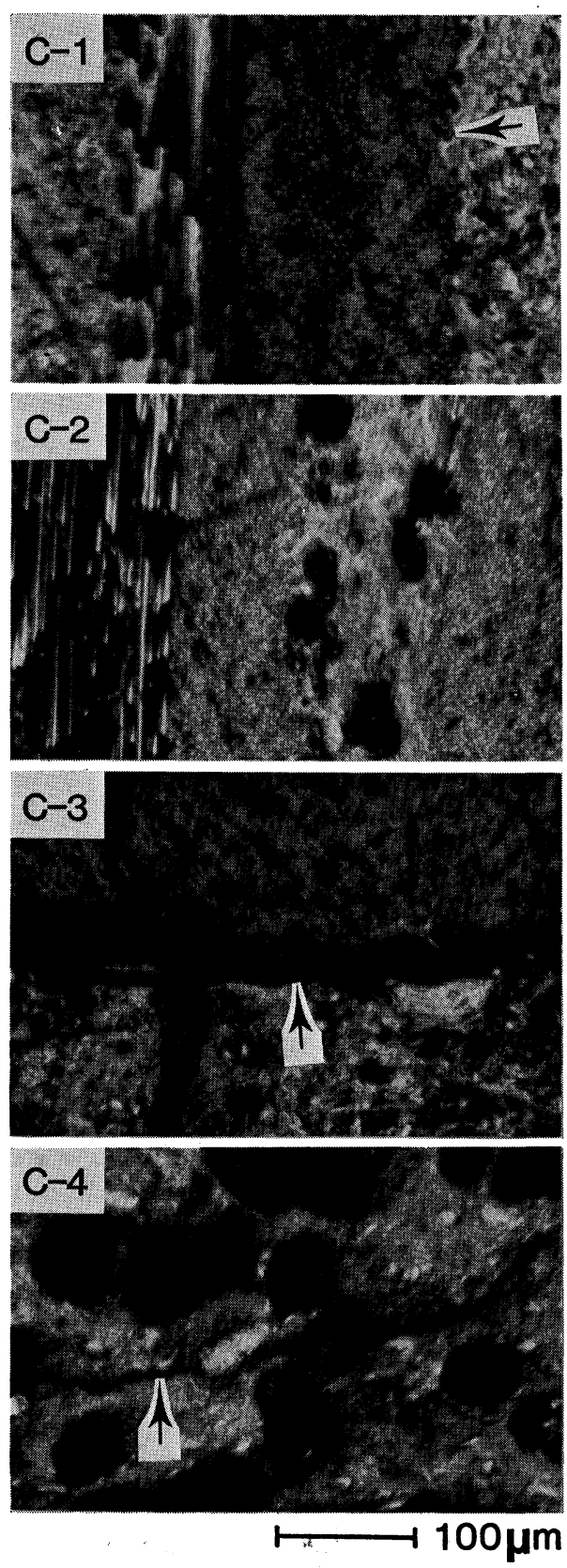

Fig. 12. Polarized light microphotographs of a $\mathrm{C} / \mathrm{C}$ composite cross section using CL-2 fibers (BM ratio= $80 \%$ ).

sented in Fig. 6 can not be described from the results of observation on the sections of specimens.

\section{Structure Observed on Section of Specimen after Heat}

\section{Treatment}

Figure 13 shows the observation on the sections of the specimens (corresponding to those in Fig. 8 indicated by open circles with continuous line), which have been obtained from a primary product fabricated with UD-2 fibers $\left(V_{f}=30.7 \%\right.$, BM ratio $80 \%$ ) by heat treating them up to $1500^{\circ} \mathrm{C}$.

The primary product baked at $600^{\circ} \mathrm{C}$ corresponds to the specimens having the $V_{f}$ value $30.7 \%$ in Fig. 5 , and its section structures is already described above. For the specimen heat-treated at $700^{\circ} \mathrm{C}$, pores of $50 \mu \mathrm{m}$ are much perceived in the matrix, and some microcracks as indicated by Photo D-1 in Fig. 13 are 


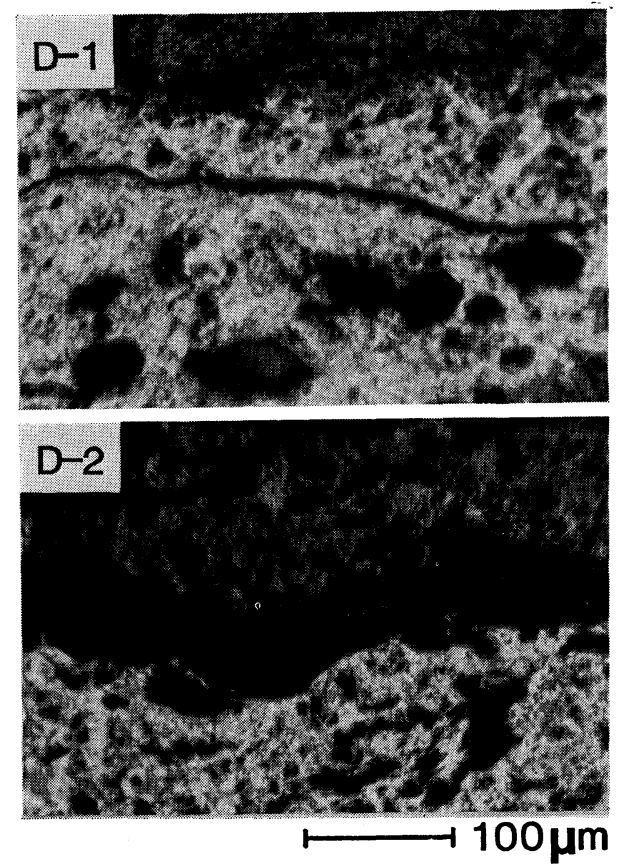

Fig. 13. Polarized light microphotographs of cross section of specimens heat-treated up to $1500^{\circ} \mathrm{C}$ on primary products using UD-2 fibers (BM ratio $=80 \%$, $V_{f}=30.7 \%$ ).

also discerned. For the specimens heat-treated at 1000 and $1200^{\circ} \mathrm{C}$, they have yielded approximately the same section structure with less generation of pores $(50 \mu \mathrm{m})$ and more generation of microcracks (Photo D-1) than the one treated at $700^{\circ} \mathrm{C}$, and there are some separate layers (Photo D-2) at the boundary between fibers and matrix. For the specimen heattreated at $1500^{\circ} \mathrm{C}$, longer microcracks are perceived in the matrix layers, and more missing fiber parts discerned in the fiber layers.

Thus heat treatment of primary products will generate microcracks and separate layers, and the amount of microcracks generated increases with HTT. Accordingly this generation of microcracks and separate layers has presumably caused the drop of $\sigma_{\max }$ in compliance with increase of HTT when UD fibers are used (see Fig. 8).

\section{Conclusion}

The authors tried to fabricate $\mathrm{G} / \mathrm{G}$ composites by a simple hot-press process using fine pulverized coke and carbonaceous bulk mesophase as matrix and unidirectional long fibers or cloths impregnated with resin as reinforcement. The obtained results are as follows:

(1) The $V_{f}$ value of each specimen as primary products for $\mathrm{G} / \mathrm{C}$ composites using the UD fibers can be raised by increasing the $\mathrm{BM}$ ratio in the matrix, and also by using thicker prepreg sheets in case such having the same $V_{f}$ value are laminated with BM ratio held constant.

(2) When UD fibers are used, the strength of primary products maximizes at the $\mathrm{BM}$ ratio in matrix $70 \%$ and with the $V_{f}$ value approximately $30 \%$ in case with UD-1 and at the BM ratio $80 \%$ and with the $V_{f}$ value $46.4 \%$ in case with UD-2, the latter being a little higher. When cloths are used, the strength maximizes at the $V_{f}$ value approximately $20 \%$ in both cases with CL-1 and CL-2, which is however much lower than the maximum strength when UD fibers are used.

(3) The G/G composite fabricated through hotpress process using resin-impregnated UD fibers (UD2) has its maximum strength at a certain optimum hot-pressing pressure, which is $49 \mathrm{MPa}$ at $600^{\circ} \mathrm{C}$.

(4) Primary products using UD-2 and CL-2 lose their strengths through heat treatment: The strength using UD fibers falls to $80 \mathrm{MPa}$ and stabilizes there. As far as primary products using UD fibers are concerned, the maximum strength marks 119 and 130 $\mathrm{MPa}$ for UD-1 and UD-2, respectively, which are higher than the strength of the commercial $\mathrm{G} / \mathrm{C}$ composite.

\section{Acknowledgements}

Thanks are due to Koa Oil Co., Ltd. which offered carbonaceous bulk mesophase used in this study, as well as Nippon Carbon Co., Ltd. which provided us with carbon fibers necessary for experiments.

\section{REFERENCES}

1) E. Fitzer and A. Burger: Ext. Abst., "Int'l Conf. on Carbon Fibers, their Composites and Applications", London, 1971, Paper No. 36.

2) W. Kotlensky: Chem. and Phys. of Carbon, 9 (1973), 174.

3) T. Cho and A. Okura: "Manufacture of Carbon-Carbon Composites by Using Fine Coke and Its Properties ", Recent Advances in Composites in the United States and Japan, ASTM Spe. Tech. Publ. No. 864, J. R. Vinson and M. Taya, Ed., ASTM, Philadelphia, (1985), 443.

4) M. Anzai and A. Okura: Seisan-Kenkyu, 37 (1985), 265.

5) T. Chang and A. Okura: Tanso, 123 (1985), 150. 